\title{
Dissolution inhibition of bismuth, lead, tin and their ternary alloys in chloride solution
}

\author{
V. V. Ekilik, ${ }^{1 *}$ E. A. Korsakova, ${ }^{1}$ A. G. Berezhnaya, ${ }^{1}$ E. A. Levinskaya ${ }^{2}$ \\ and K. V. Chaikovsky ${ }^{1}$ \\ ${ }^{1}$ Southern Federal University, ul. Zorge 7, Rostov-on-Don, \\ 344090 Russian Federation.*E-mail: v.ekilik@yandex.ru \\ ${ }^{2}$ Rostov State University of Civil Engineering, ul. Sotsialisticheskaya 162, \\ Rostov-on-Don, 344022 Russian Federation
}

\begin{abstract}
The behavior of bismuth, lead, tin, and their ternary alloys in $0.1 \mathrm{M} \mathrm{NaCl}$ solution in the presence of certain organic additives has been studied. The effect of 9-aminoacridine, benzimidazole, and oleate on metals and alloys has been compared. It has been found that the alloy composition affects the inhibition efficiency.
\end{abstract}

Key words: inhibitors, bismuth, lead, tin, alloys, anodic dissolution, sodium chloride solution, passivation, depassivation.

Received: August 2, 2013.

$\underline{10.17675 / 2305-6894-2013-2-3-224-230}$

\section{Introduction}

Low-melting heterogeneous alloys are widely used in the soldering of integrated circuits. However, their corrosion and electrochemical behavior and effects of organic additives have been studied insufficiently and mostly for binary systems [1-6]. It appeared expedient to consider ternary alloys having lower melting points and to find out whether they can be protected by inhibitors in a broad potential range.

\section{Experimental}

Specimens of $14 \mathrm{Bi} 43 \mathrm{Sn} 43 \mathrm{~Pb}$ and $46 \mathrm{Bi} 34 \mathrm{Sn} 20 \mathrm{~Pb}$ alloys (the numbers before the metals show the mass percentages of the components) shaped as cylinders were made from solders. A solder is a paste-like uniform compound containing, in addition to the metals, also rosin and polyglycol ether that is removed on heating. Test tubes with an alloy were kept for $3 \mathrm{~h}$ at $350^{\circ} \mathrm{C}$ and cooled along with the furnace. The remaining solidified organic admixtures were mechanically removed with a fraction of the alloy. Electrodes with a discshaped working surface (area $\sim 0.2 \mathrm{~cm}^{2}$ ) embedded in solidified epoxy resin were mechanically abraded, polished, and cathodically activated in the working solution before the measurements. The activation was carried out for $15 \mathrm{~min}$ at a current density of $i_{c}=$ $100 \mathrm{~A} / \mathrm{m}^{2}$, with simultaneous bubbling of purified electrolytic hydrogen.

Forward anodic polarization curves and reverse curves were recorded in a temperature-controlled $\left(25 \pm 0.2^{\circ} \mathrm{C}\right)$ three-electrode cell. The potential $(E)$ was varied in a 
stepwise manner (step $=50 \mathrm{mV}$, exposure for $1 \mathrm{~min}$ at each potential). The $E$ values refer to saturated silver/silver chloride electrode. All the measurements were carried out in $0.1 \mathrm{M} \mathrm{NaCl}$ solution, in some cases containing $1 \mathrm{mmol} / 19$-aminoacridine or $5 \mathrm{mmol} / \mathrm{l}$ benzimidazole or potassium oleate. The effect of the additives was estimated by the inhibition factor $\gamma$ calculated as the ratio of the rates in the reference solution and in the solution containing an additive.

\section{Results and Discussion}

In the reference solution, primary passive dissolution of metals ends in local depassivation at $E_{\mathrm{dp}}$ followed by repassivation at $E_{\mathrm{rp}}$; as a result, a peak at $E_{\mathrm{ap}}$ appears on the curve (Fig. 1). On tin, depassivation is preceded by two stepwise passivation peaks corresponding to the formation of $\mathrm{SnO}$ and $\mathrm{SnO}_{2}$ [7], whereas depassivation on lead and tin is preceded by intermediate activation due to a decrease in the salt basicity $[8,9]$. Lead repassivation is caused by the formation of a poorly-soluble normal salt, whereas that of tin and bismuth is due to hydrolysis products, since tin chloride is well soluble and bismuth chloride readily undergoes hydrolysis. The second depassivation-repassivation peak observed on lead is most likely due to an increase in its oxidation state. The $E_{\mathrm{dp}}$ and $E_{\mathrm{ap}, 1}$ values increase in the series: lead, tin, bismuth. Hence, bismuth is the most resistant to depassivation, whereas lead is the least resistant. However, repassivation of lead occurs before that of the other metals.

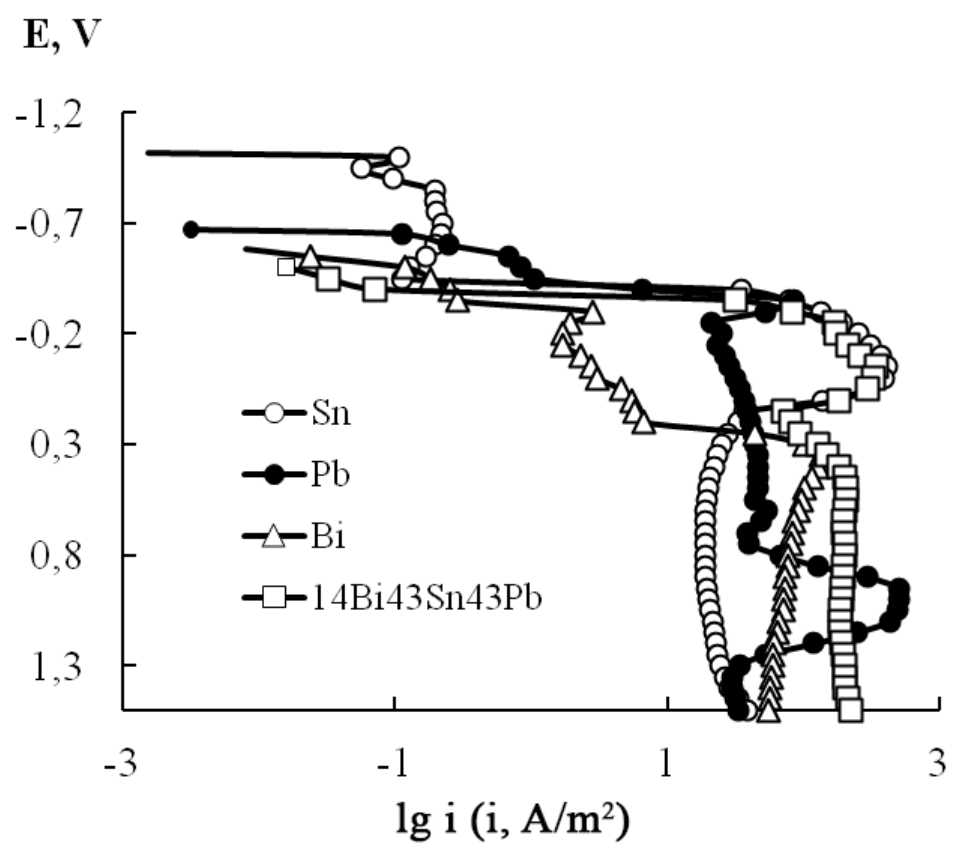

Figure 1. Forward anodic polarization curves of the metals and an alloy.

The anodic curves have different passivation, depassivation and repassivation regions. Furthermore, the characteristic potentials and currents depend on the metal nature in different ways. Therefore, the comparative resistance of the metals against dissolution, as well as (provided that the principle of independence of electrode reactions is observed) against corrosion, changes with potential (Fig. 1). 
In the initial region of passive dissolution, the anodic reaction rate of the $14 \mathrm{Bi} 43 \mathrm{Sn} 43 \mathrm{~Pb}$ alloy is considerably smaller and $E_{\text {cor }}$ is accordingly higher than those of the metals. Formation of binary or ternary metal oxides is also possible. As a result, the curve for the alloy nearly does not contain this region. Depassivation starts just after $E_{\text {cor }}$ and its rate approaches that of lead as the least resistant component. Subsequently, the curve of the alloy approaches than of tin. As a result, partial splitting of the first anodic peak occurs. Once bismuth depassivation occurs, this component starts to govern the dissolution of the alloy. However, the dissolution rate of the heterogeneous alloy has the maximum value, though it should have an intermediate value if its components dissolve independently. This is possible if the repassivating films interfere with the formation of each other, in particular, due to different reasons of phase formation as described above. Under these conditions, dissolution can be localized at the crystal boundaries of different metals and enhance non-uniform dissolution of the alloy in comparison with the metals. The latter factor is likely to be one of the reasons for disappearance of secondary activation and of the second peak characteristic of lead, though the concentration of lead in the alloy is rather high.

The alloy composition does not affect depassivation. Partial replacement of lead and tin for bismuth facilitates repassivation but considerably increases the current density at potentials of bismuth depassivation (Fig. 2).

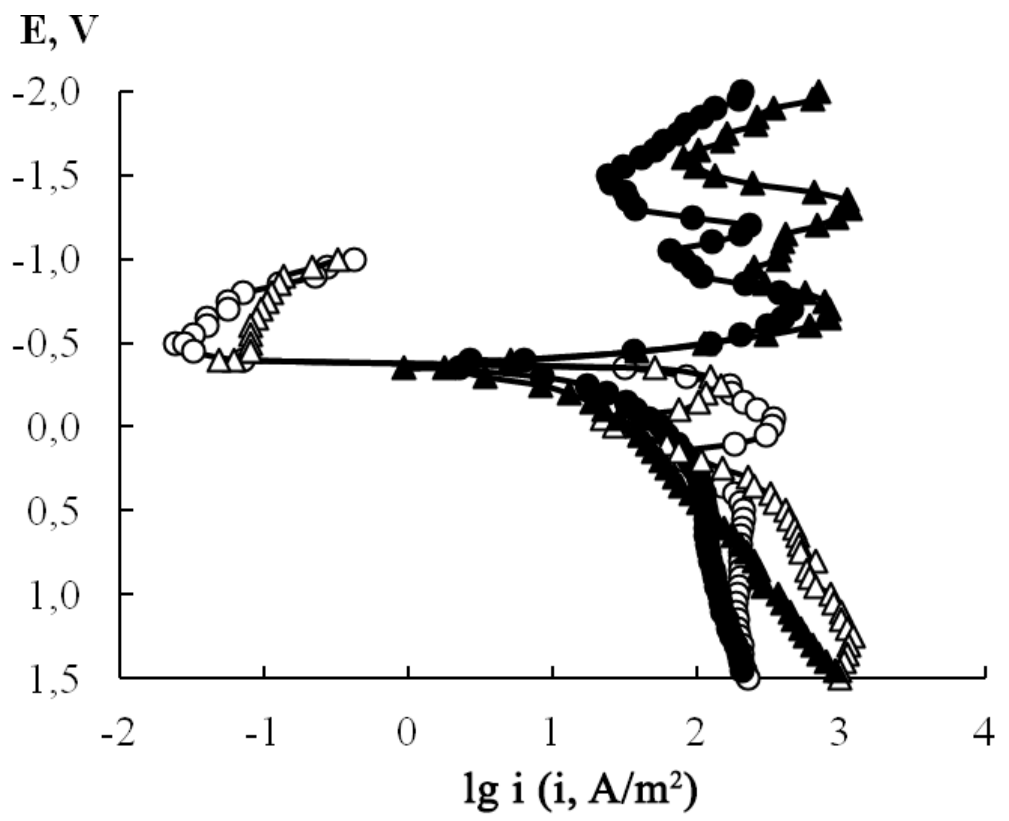

Figure 2. Forward $(\circ, \Delta)$ and inverse $(\bullet, \boldsymbol{\Delta})$ polarization curves on $14 \operatorname{Bi} 43 \operatorname{Sn} 43 \mathrm{~Pb}(\circ, \bullet)$ and $46 \mathrm{Bi} 34 \mathrm{Sn} 20 \mathrm{~Pb}(\Delta, \boldsymbol{\Delta})$ alloys.

The intensity of peaks on the reverse curve for the 46Bi34Sn20 Pb alloy increases in comparison with the $14 \mathrm{Bi} 43 \mathrm{Sn} 43 \mathrm{~Pb}$ alloy, which suggests that the thickness of the repassivating film increases and agrees with the decrease in its protective properties. 
The effect of organic additives depends on the metal nature and is a combination of inhibition and stimulation. The effect of 9-aminoacridine on bismuth is only observed between the two anodic peaks; the inhibition factor is $\gamma=1.3-2.2$. On tin, the additive does not affect the coordinates of the anodic peak. It inhibits dissolution before the peak more strongly $(\gamma=5-6)$ than after the peak $(\gamma \approx 2)$. It inhibits the process on lead by a factor of $1.7-3$ at $E<E_{\mathrm{dp}, 1}$, suppresses the first peak, and increases $E_{\mathrm{dp}, 2}$ by $100 \mathrm{mV}$. No similarity was found in the effects of 9-aminoacridine on the metals and alloys. On the $46 \mathrm{Bi} 34 \mathrm{Sn} 20 \mathrm{~Pb}$ alloy, $E_{\text {ap }}$ increases by $100 \mathrm{mV}$ and the process at $E>E_{\text {ap }}$ is inhibited 1.6fold. On 14Bi43 $\mathrm{Sn} 43 \mathrm{~Pb}$, the shift of the anodic peak increases to $200 \mathrm{mV}$, but no inhibition occurs at $E>E_{\text {ap. }}$.

Many features of the benzimidazole effect on the dissolution of lead and tin are similar (Fig. 3). It either nearly does not affect the process rate on lead or stimulates it. There is no effect under the oxide and chloride film. However, the additive facilitates secondary depassivation and hinders primary and secondary repassivation. This effect is usually possible if soluble metal complexes are formed. It is suppressed by primary repassivation but predominates over secondary repassivation. On tin, benzimidazole nearly does not affect primary passivation and increases $E_{\mathrm{dp}, 1}$ by only $50 \mathrm{mV}$. It decreases the rate of local depassivation but hinders repassivation. It causes secondary depassivation (which does not occur in the solution without the additive) that is not followed by repassivation. In case of bismuth dissolution, benzimidazole, like 9-acridine, behaves as an inhibitor in the potential region between the two anodic peaks $(\gamma=5-10)$.

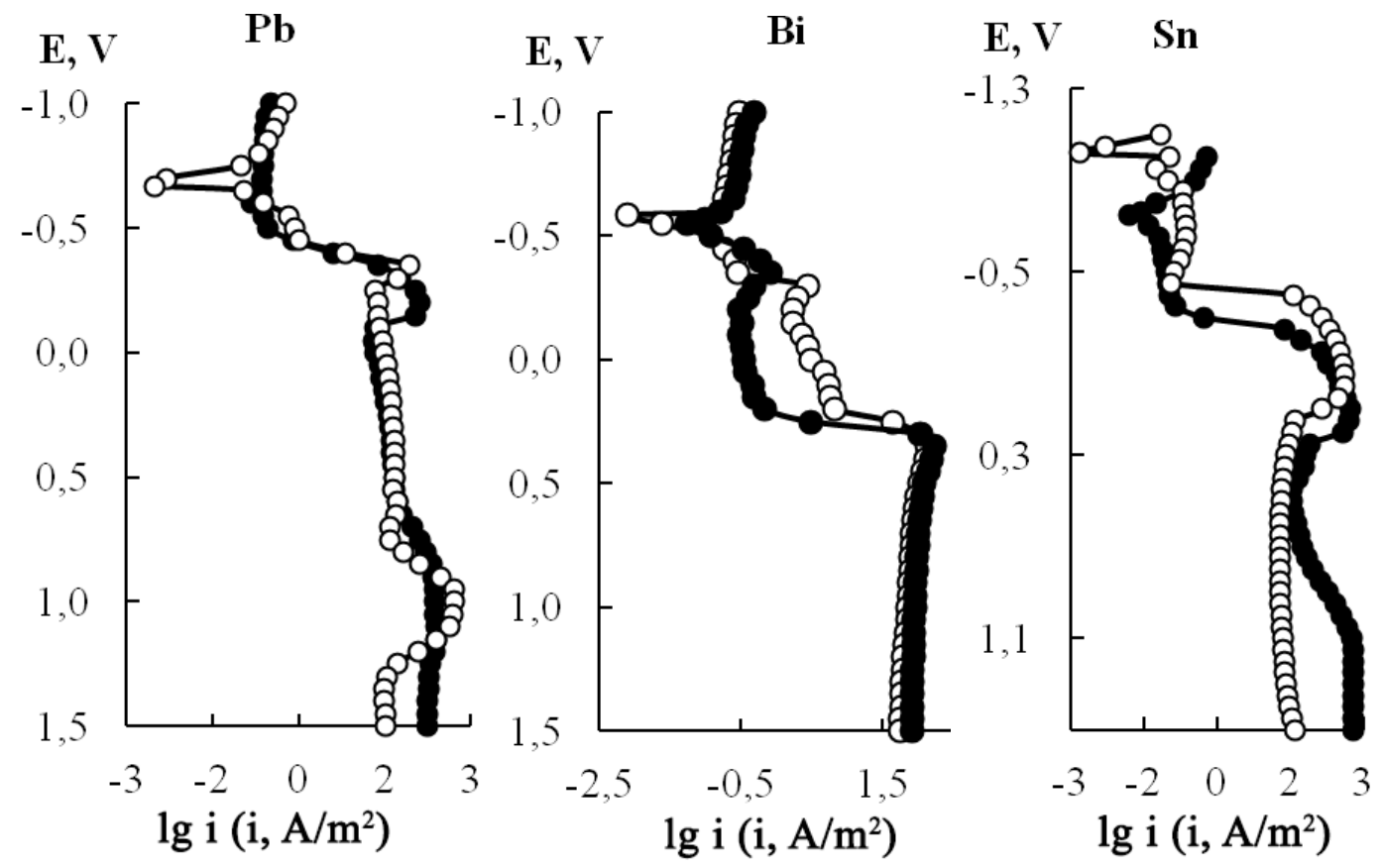

Figure 3. Polarization curves on the metals in solutions without additives $(\circ)$ and in the presence of benzimidazole $(\bullet)$. 
Despite the differences in the effects of the additive on the dissolution of the metals, the alloy composition nearly does not affect the magnitudes of the effect and their dependence on $E$ (Fig. 4).
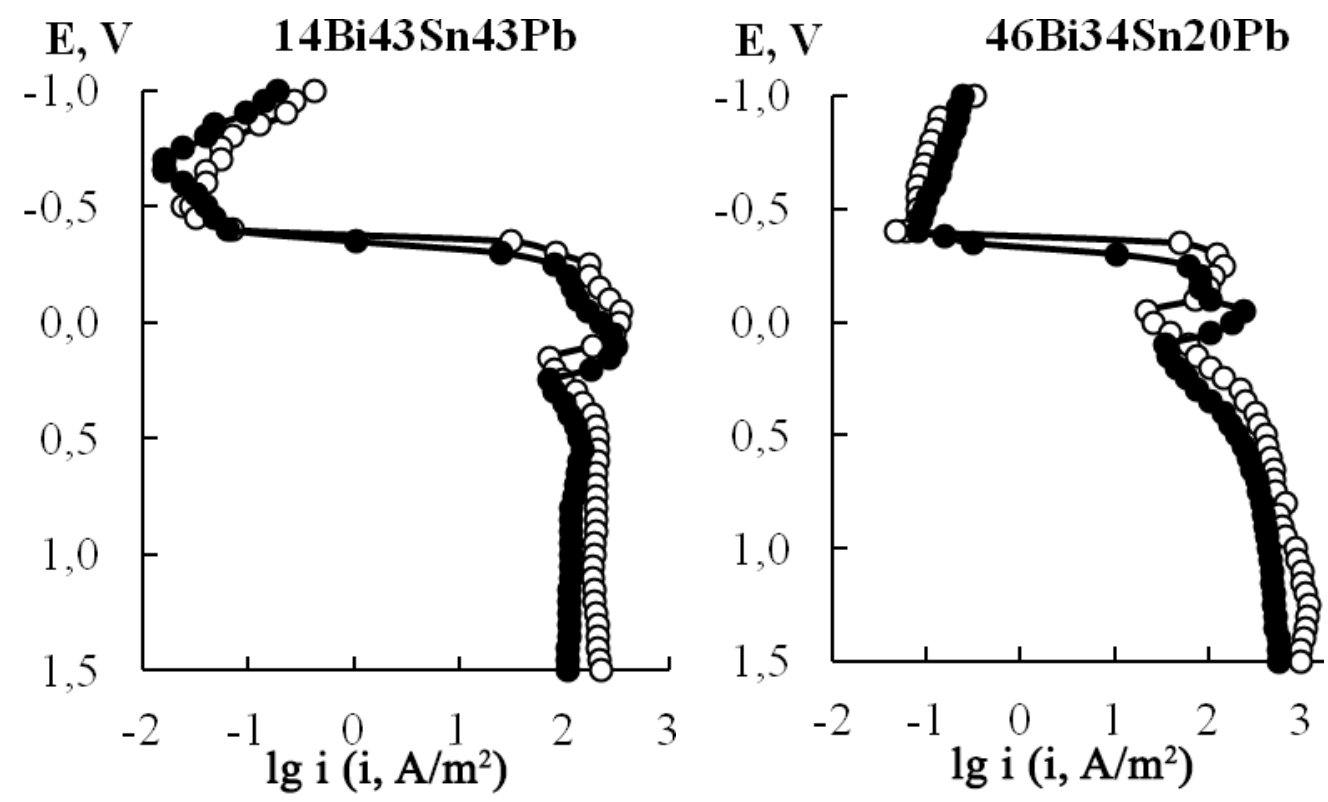

Figure 4. Polarization curves on the alloys in solutions without additives $(\circ)$ and in the presence of benzimidazole $(\bullet)$.

The reason is probably that the behavior of alloys before the end of the first peak is mostly determined by tin whose content in the alloys differs insignificantly. At high $E$ values, the alloys behave anomalously, both in terms of dissolution rates (Fig. 1) and in the effects of benzimidazole (Fig. 4). The effect of the alloy composition manifests itself in the change in the "anti-pitting basis", $\Delta E=E_{\mathrm{dp}}-E_{\text {cor }}$. On the $46 \mathrm{Bi3} 4 \mathrm{Sn} 20 \mathrm{~Pb}$ alloy, $\Delta E \approx 0 \mathrm{~V}$ and it does not depend on the additive. However, on the $14 \mathrm{Bi} 43 \mathrm{Sn} 43 \mathrm{~Pb}$ alloy where $\Delta E \approx$ $100 \mathrm{mV}$, the additive increases $\Delta E$ by $200 \mathrm{mV}$.

Though benzimidazole and oleate belong to different groups of surface-active compounds, their effects on the anodic curves of bismuth [10], lead [11], tin, and the alloys (Figs. 4,5) are similar. This fact may be due to the same type of their effect on phase formation processes. The difference mainly concerns the magnitudes of the effects. Oleate increases $E_{\mathrm{dp}}, \Delta E$, and $E_{\mathrm{ap}}$ to a greater extent.

\section{Conclusions}

Anodic curves of tin, lead, bismuth, and their ternary alloys are characterized by passive state, local depassivation, and repassivation regions. The ratio between the metal dissolution rates depends on potential. As the potential increases, lead, tin and bismuth in turn become the least resistant. These components make the major contribution to the dissolution of the alloys. Primary passive dissolution of the alloys occurs at a lower rate than the rate that might be expected based on the rates for the metals, whereas secondary 
dissolution occurs at a higher rate. On transition from $14 \mathrm{Bi} 43 \mathrm{Sn} 43 \mathrm{~Pb}$ to $46 \mathrm{Bi} 34 \mathrm{Sn} 20 \mathrm{~Pb}$, the role of tin in the dissolution process decreases, whereas that of bismuth increases.

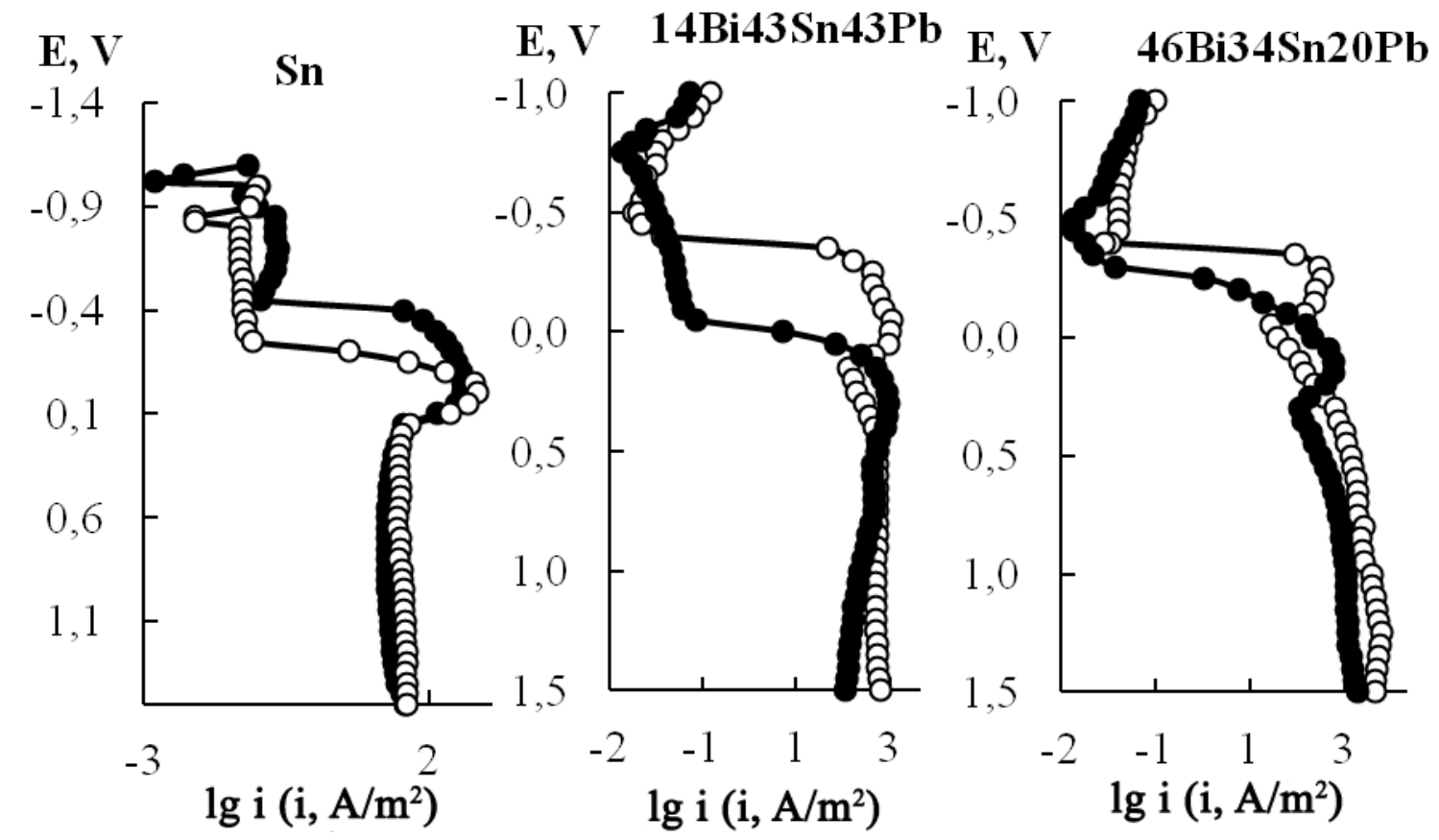

Figure 5. Polarization curves on the alloys in solutions without additives $(\circ)$ and in the presence of potassium oleate $(\bullet)$.

The effects of 9-aminoacridine on the dissolution of metals and alloys do not show similarities. Benzimidazole and potassium oleate affect the dissolution of the alloys in a similar way, but oleate is more efficient. In the primary passivation, depassivation, and repassivation states, the effects of these additives are primarily determined by the tin and lead components, whereas at higher potentials the effects are not related to inhibition of metal dissolution and depend on alloy composition. An increase in lead content instead of bismuth increases the pitting resistance upon addition of benzimidazole and especially oleate to the solution.

\section{References}

1. Nguen Dik Kim and A. M. Sukhotin, Zashch Met., 1989, 25, 945 (in Russian).

2. A. G. Berezhnaya and V. V. Ekilik, Korroz.: Mater. Zashch., 2007, no. 2, 6 (in Russian).

3. V. V. Ekilik, A. A. Gerashchenko and A. G. Berezhnaya, Korroz.: Mater. Zashch., 2008, no. 8, 8 .

4. V. V. Ekilik, A. G. Berezhnaya, G. N. Ekilik and U. V. Dovbnya, Korroz.: Mater. Zashch., 2010, no. 3, 21 (in Russian).

5. A. G. Berezhnaya, P. I. Ogarev and V. V. Ekilik, Korroz.: Mater. Zashch., 2012, no 2, 16 (in Russian). 
6. A. G. Berezhnaya, V. I. Mishurov and V. V. Ekilik, Korroz.: Mater. Zashch., 2012, no. 4, 16 (in Russian).

7. Nguen Dik Kim and A. M. Sukhotin, Zh. Prikl. Khim., 1990, no. 8, 1737 (in Russian)

8. V. V. Ekilik, K. S. Tikhomirova, A. G. Berezhnaya and E. A. Levinskaya, Korroz.: Mater. Zashch., 2012, no 2, 1 (in Russian).

9. V. V. Ekilik, E. A. Korsakova, A. G. Berezhnaya and E. I. Momotova, Korroz.: Mater. Zashch., 2012, no. 12, 1 (in Russian).

10. V. V. Ekilik, E. A. Korsakova and A. G. Berezhnaya, Int. J. Corros. Scale Inhib. 2013, no. 1, 30. doi: 10.17675/2305-6894-2013-2-1-030-038

11. V. V. Ekilik, E. A. Korsakova, A. G. Berezhnaya and K. S. Tikhomirova, Materials of the international scientific and practical conference "Current problems of electrochemistry and corrosion protection in dealing with environmental problems", Tambov, Tambov State University Publishing House, 2012, 165 (in Russian). 